\title{
A UAV and S2A data-based estimation of the initial biomass of green algae in the South Yellow Sea
}

\author{
Fuxiang $\mathrm{Xu}^{\mathrm{a}, \mathrm{b}, \mathrm{d}}$, Zhiqiang $\mathrm{Gao}^{\mathrm{a}, \mathrm{c}, *}$, Xiaopeng Jiang ${ }^{\mathrm{a}}$, Weitao Shang ${ }^{\mathrm{a}}$, Jicai Ning ${ }^{\mathrm{a}}$, Debin Song ${ }^{\mathrm{a}, \mathrm{b}}$, \\ Jinquan $\mathrm{Ai}^{\mathrm{e}}$ \\ ${ }^{a}$ Yantai Institute of Coastal Zone Research, Chinese Academy of Sciences, Yantai 264003, China \\ ${ }^{\mathrm{b}}$ University of Chinese Academy of Sciences, Beijing 100049, China \\ ${ }^{\mathrm{c}}$ Key Laboratory of Coastal Environmental Processes and Ecological Remediation, Yantai Institute of Coastal Zone Research, Chinese Academy of Sciences, Yantai 264003, \\ China \\ d School of Public Administration, Shandong Technology and Business University, Yantai 264005, China \\ ${ }^{\mathrm{e}}$ Key Laboratory of Geographic Information Science, Ministry of Education, East China Normal University, Shanghai 200241, China
}

\section{A R T I C L E I N F O}

\section{Keywords:}

Green algae

Biomass

UAV

S2A

Pyropia aquaculture raft

Yellow Sea

\begin{abstract}
A B S T R A C T
Previous studies have shown that the initial biomass of green tide was the green algae attaching to Pyropia aquaculture rafts in the Southern Yellow Sea. In this study, the green algae was identified with unmanned aerial vehicle (UAV), an biomass estimation model was proposed for green algae biomass in the radial sand ridge area based on Sentinel-2A image (S2A) and UAV images. The result showed that the green algae was detected highly accurately with the normalized green-red difference index (NGRDI); approximately 1340 tons and 700 tons of green algae were attached to rafts and raft ropes respectively, and the lower biomass might be the main cause for the smaller scale of green tide in 2017. In addition, UAV play an important role in raft-attaching green algae monitoring and long-term research of its biomass would provide a scientific basis for the control and forecast of green tide in the Yellow Sea.
\end{abstract}

\section{Introduction}

Green tide is an abnormal marine ecological phenomenon existing in coastal areas, and its massive outbreak has been reported around the world, such as in Brittany, a coastal area of France, as well as many coastal states in Europe, American and Asia (Blomster and Stanhope, 2002; Charlier et al., 2015; Hiraoka et al., 2004; Lapointe et al., 2005; Nelson et al., 2003). After the outbreak of green tide, a great amount of green algae are buoyant on seawater and go with the ocean current to cover whole offshore waters and tidal-flat bathing places to destroy the marine ecosystem, gravely threatening the local tourism, aquaculture and fishery. This suggests that green tide disasters have become a worldwide marine ecological issue (Lyons et al., 2014; Smetacek and Zingone, 2013; Wang et al., 2012). Since 2007, the world's largest green tide disaster has been breaking out in the South Yellow Sea for 10 consecutive years (Qi et al., 2016), causing a heavy economic and ecological loss to the local related industries. Reportedly, nearly 10 billion RMB of losses were caused in 2008 alone, and this attracted widespread attention from home and abroad, in particular the local government (Wang et al., 2009).
To clarify the formation mechanism of green tide disasters, global researchers have done a lot of work, and it's widely believed that seawater eutrophication and global change should be the first to blame for this problem. For the green tide disaster in the South Yellow Sea, some scholars have investigated it for years through remote sensing monitoring, discovering that the green tide in the South Yellow Sea originally came from radial sand ridges; and the green algae on large-scale $P$. yezoensis aquaculture rafts in the radial sand ridge area contained huge biomass, which provided initial biomass for the massive propagation of green tide in the South Yellow Sea (Liu et al., 2009, 2010; Keesing et al., 2011). A great number of research results indicated that besides water eutrophication and global changes, large quantities of green algae dislodged from the rafts as a result of harvesting practices in the Southern Yellow Sea provided initial biomass for the recurrence of green tide (Liu et al., 2013; Zhang et al., 2011). Massive green algae attaching to $P$. yezoensis aquaculture rafts enters the sea for natural or artificial reasons around April and May every year, and then drifts to the coast of Shandong Peninsula with the ocean current and wind; the biomass of green tide increases rapidly under suitable light and nutrient conditions in the drift process, and finally causes a green tide disaster

\footnotetext{
* Corresponding author at: Yantai Institute of Coastal Zone Research, Chinese Academy of Sciences, Yantai 264003, China.

E-mail address: zqgao@yic.ac.cn (Z. Gao).
} 

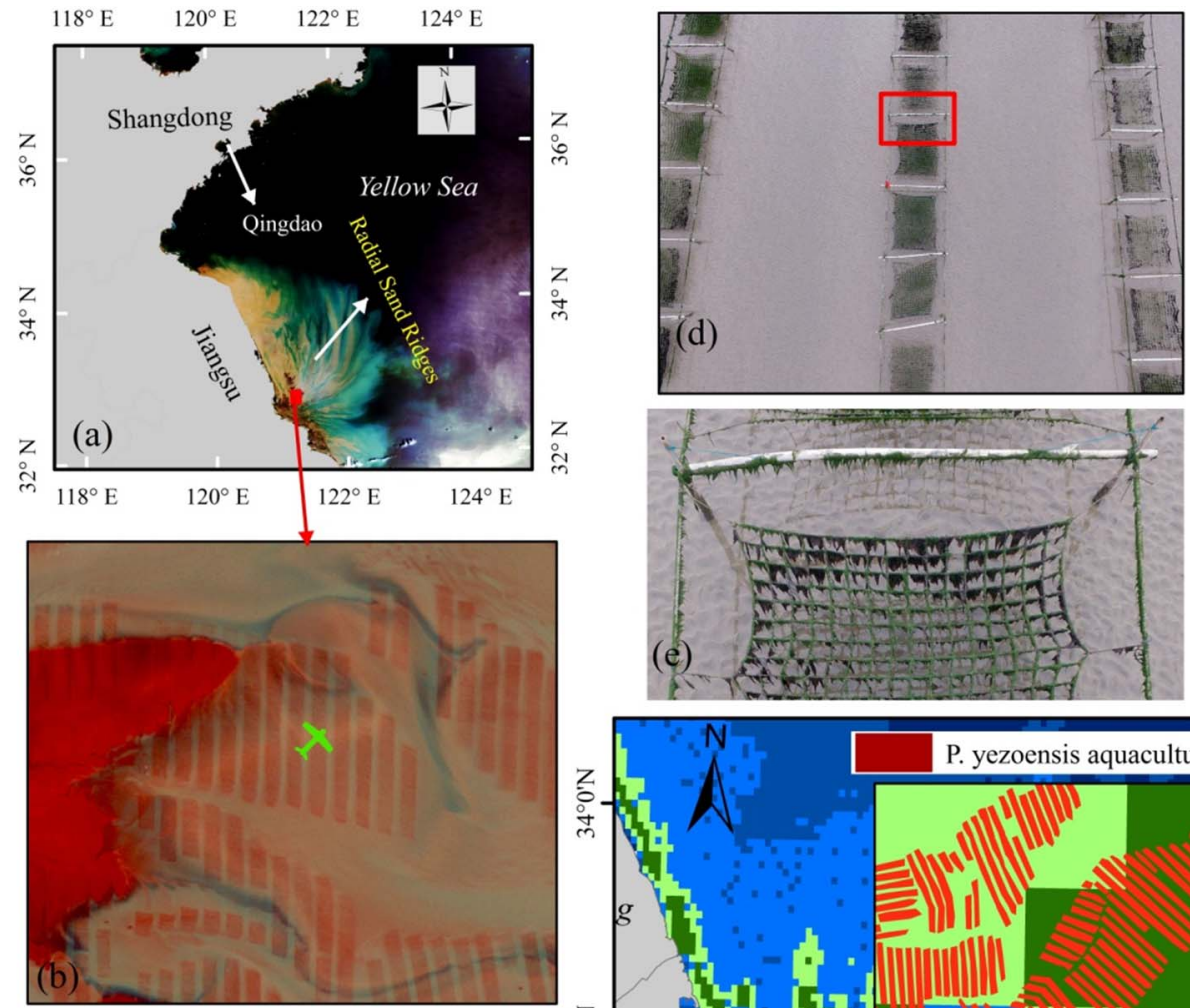

in
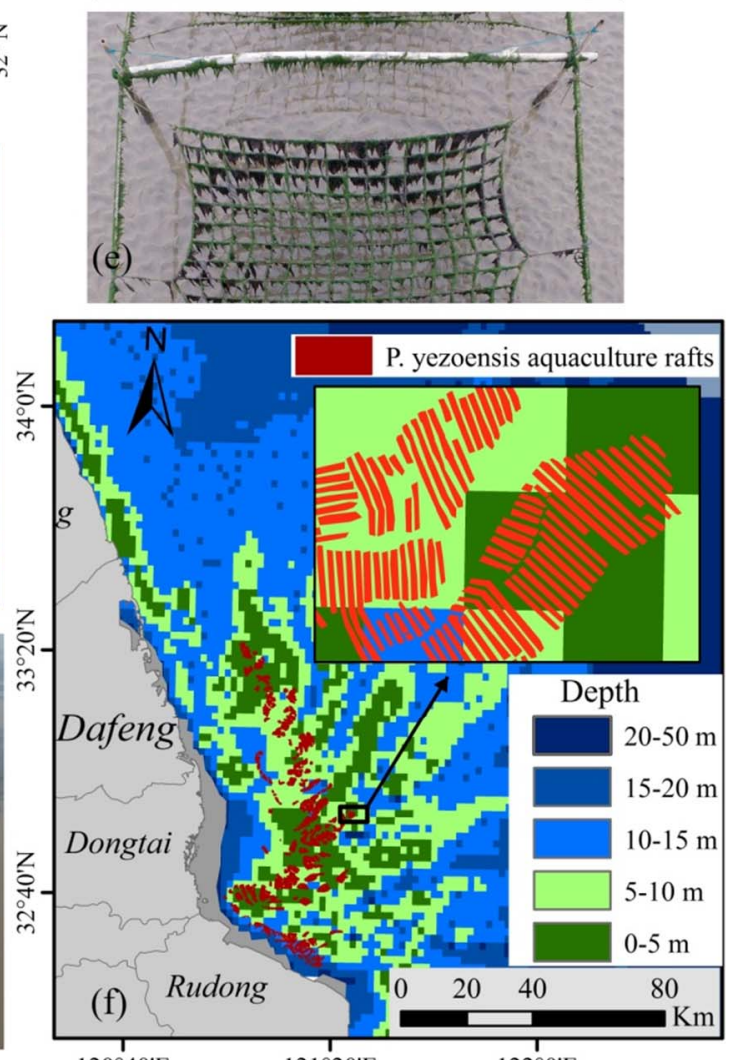

Fig. 1. Study area and P. yezoensis aquaculture rafts: (a) the radial sand ridge area in the Yellow Sea, marked by white arrow; (b) S2A pseudocolor image of $P$. yezoensis aquaculture rafts; (c) UAV image of $P$. yezoensis aquaculture rafts which are arranged in a rectangular arrangement; (d) UAV image of $P$. yezoensis aquaculture rafts which are arranged chain-like in the rectangular patches; (e) UAV image marked in the red rectangle in panel d; each raft consists of two bamboo poles, two pieces of rope and one nursery net; (f) distribution map of $P$. yezoensis aquaculture rafts in the radial sand ridge area. (For interpretation of the references to color in this figure legend, the reader is referred to the web version of this article.)

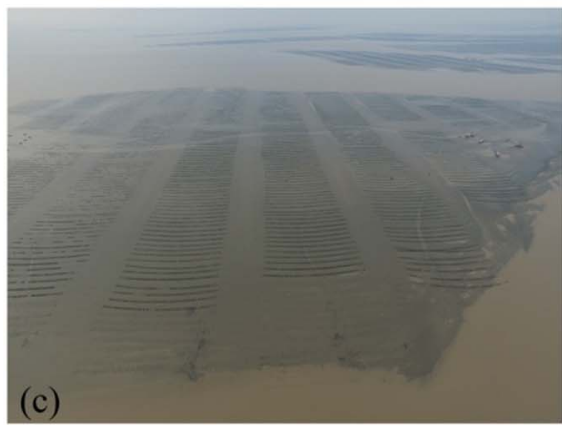

$120^{\circ} 40^{\prime} \mathrm{E}$

$121^{\circ} 20^{\prime} \mathrm{E}$

$122^{\circ} 0^{\prime} \mathrm{E}$

(Qiao et al., 2011; Xu et al., 2014; Xing et al., 2015a, 2015b). Therefore, since the raft-attaching green algae provide initial biomass for the recurrence of green tide, its biomass may be an important indicator that decides the magnitude of green tide. Hence, a scientific and accurate evaluation of the biomass of green algae on rafts in the radial sand ridge area may be able to help reveal the formation mechanism of green tide, which has lasted a few years, and provided decision support for the forecast and management.

Hu et al. (2017) built a biomass estimation model for oceanic floating green algae using MODIS satellite images and FAI index based on laboratory spectrum and field experiments, and evaluated the biomass of the green tide that occurred in the Yellow Sea between 2008 and 2015 with this model, finding that the biomass was between $0.09 * 10^{6}$ tons and $1.7 * 10^{6}$ tons. However, compared with the largearea floating green algae patches on the sea, the green algae on rafts, which were tiny and scattered, was hard to directly monitor by remote sensing technology (Hu et al., 2010).

So nowadays, the biomass of raft-attaching green algae in the radial sand ridge area is mainly estimated in an indirect way based on samples taken from observation points. Due to different measurement and sampling methods, scholars have hypothesized different ranges in estimation result. Liu et al. (2010) collected samples from many parts of the Jiangsu coast including the radial sand ridge area, figuring out the average wet weight of the green algae on rafts, and then calculated the biomass of the raft-attaching green algae based on the Pyropia aquaculture area, evaluating the biomass that it was 4620 tons. Zhang et al. (2014) and Liu et al. (2017) interpreted and extracted the Pyropia aquaculture area of 2013 in the radial sand ridge area by satellite remote sensing technology, and then estimated the biomass of the raftattaching green algae based on the field sampled data. They argued that approximately 2784 tons of Ulva prolifera were attached to the rafts in the radial sand ridge area. Huo et al. (2015) made a more thorough investigation and estimation of the biomass of the 2013 raft-attaching green algae in the radial sand ridge area in a similar way, suggesting that the biomass of the green algae on rafts in the radial sand ridge area was more than 20,000 tons.

Most of the current studies on green algae biomass in the radial sand ridge area are subject to low accuracy since the area of $P$. yezoensis aquaculture rafts is just estimated by social survey or by reference to the statistical yearbook (Qi et al., 2016; Shang, 2008). Although some researchers have calculated the total $P$. yezoensis aquaculture area in the radial sand ridge area by satellite remote sensing and social survey, and estimated the biomass of green algae, due to the meter-scale spatial size of the $P$. yezoensis aquaculture rafts and the large gap between them, there are inevitably many mixed pixels in remote sensing images (Liu et al., 2017; Zhang et al., 2014). Because of this, the raft area will be 
unavoidably overestimated if it is calculated with remote sensing images, which will then cause the potential error in the estimated biomass of the green algae in the radial sand ridge area. This is not beneficial to the exploration of the mechanism of the green tide disaster or the establishment of an early-warning model. In the past, scholars usually estimated the initial biomass of all the green algae on rafts. But some studies show that with the improvement of the $P$. yezoensis aquaculture technology in the radial sand ridge area in recent years, perhaps only the green algae attaching to raft ropes was dislodged onto mudflat with the $P$. yezoensis harvested and then swept into the sea by the tidal current to become the initial biomass of green tide (Liu et al., 2017). Therefore, it is very necessary to build an estimation model for the initial biomass of the green tide on raft ridge ropes.

Due to its high resolution, low cost and flexibility, the unmanned aerial vehicle (UAV) has been widely used for studies on the estimation of crop biomass in recent years, providing that it is feasible to estimate biomass using a UAV (Jannoura et al., 2015; Senthilnath et al., 2016; Vega et al., 2015). Sentinel-2A image (S2A) images can be used to detect small-area ground objects with a spatial resolution of $10 \mathrm{~m}$ (Fernández-Manso et al., 2016; Lavrova, 2016). However, it hasn't ever been reported that UAV and S2A data are used to estimate the biomass of green algae on $P$. yezoensis aquaculture rafts. In this study, an initial biomass estimation model of raft-attaching green algae was built according to in-situ sampled data and satellite-UAV-ground survey. Then the initial biomass of green algae in the radial sand ridge area was estimated highly accurately in the hope of providing a scientific basis for the formation mechanism, prevention and control of green tide disasters as well as an early warning against it.

\section{Data and methodology}

\subsection{Overview of the study area and field survey methods}

Jiangsu Province has a several hundred kilometer-long shoreline, and the tidal flats, which are formed in a complex mechanism and covers an area of $5000 \mathrm{~km}^{2}$. The depth of the tidal flats is not more than $20 \mathrm{~m}$, so $P$. yezoensis can be easily planted by semi-floating method there (Fig. 1). Usually, $P$. yezoensis aquaculture begins in September or October, and harvest ends in April of the year ensuing, when aquaculture rafts are removed. During the removal of rafts, lots of green algae are peeled from rafts and thrown into the sea, becoming the initial biomass of green tide. In recent years, the aquaculture area of $P$. yezoensis has increased rapidly in the North Jiangsu shoal. In particularly, the aquaculture of $P$. yezoensis in the radial sand ridge area has increased from in $30 \mathrm{~km}^{2}$ in 2000 to $350 \mathrm{~km}^{2}$ in 2013 (Liu et al., 2017; Zhang et al., 2014).

In order to investigate the raft-attaching green algae in the $P . y e-$ zoensis aquaculture zone, the scientific investigation personnel made observations and collected samples at fixed points by UAV on the spot on a rented fishing vessel for a week (5 to 12 May). During the fixedpoint observations, we used DJ Ispire 1 for aerial photographing. The system consists of one flight vehicle, two remote-controllers and two displays. Carrying a DJI X3 digital camera, the UAV monitored the targets by scanning them, and the GPS in the flight vehicle fixed each image by position lines. Meanwhile, the pan tilt zoom control system was used to send live image data to the ground control station in real time. During the whole observation period, the UAV scanned several complete raft zones orthographically close-by $121^{\circ} 17^{\prime} 34^{\prime \prime}$ east longitude and $32^{\circ} 47^{\prime} 17^{\prime \prime}$ north latitude. Meantime, we chose 6 typical corresponding rafts to sample and measured the wet weight of green algae on each raft. The mean wet weight of green algae was calculated by summing the wet weight of all samples and dividing by the length of ropes sampled.

\subsection{Acquisition of UAV data and identification of raft-attaching green algae}

The raft-based aquaculture zone was photographed from an orthographic angle using a UAV at the height of over $100 \mathrm{~m}$, and then the orthophotos were processed by mosaic technique with Pix4Dmapper, generating ortho-images. Based on UAV true-color RGB images, some indexes including the normalized green-red difference index (NGRDI), normalized green-blue difference index (NGBDI), green leaf index (GLI) and (excess green) EXG were used to identify the green tide algae on rafts, and an accuracy evaluation was carried out according to survey data collected at in-situ sampling points. A formula of the four parameters is as follows:

$$
\begin{aligned}
& \text { NGRDI }=(G-R) /(G+R) \\
& \text { NGBDI }=(G-B) /(G+B) \\
& \text { GLI }=(2 G-R-B) /(2 G+R+B) \\
& \mathrm{EXG}=2 G-R-B
\end{aligned}
$$

$\mathrm{R}, \mathrm{G}$ and $\mathrm{B}$ respectively represent the DN values on the red band, green band and blue band. The theoretical value of NGRDI, NGBDI and GLI ranges from -1 to 1 , and the theoretical value of EXG ranges from -510 to 510 .

\subsection{Satellite image processing and raft area estimation}

$P$. yezoensis aquaculture technology demands that there should be proper spacing between rafts that can facilitate day-to-day aquaculture management (Fig. 1b, c, d), and this is a reason for big errors caused when a low-resolution satellite (with mixed pixels) is used for interpretation and statistics of the raft aquaculture area. Therefore, S2A images with a spatial resolution of $10 \mathrm{~m}$ were adopted in combination with orthophotos taken by a UAV in this study in order that mixed pixels should be prevented from affecting rafts area extraction. The S2A image data was offered by European Space Agency, and ACOLITE tool was used for geometric correction and atmospheric correction.

The distribution area $\boldsymbol{D}$ (with mixed pixels) of $P$. yezoensis raft was extracted in a man-machine interactive mode. Specifically, an NDVI value distribution map was generated for the target zone first, and then the raft polygons were extracted one by one accurately in ENVI 5.3 based on false-color images (Fig. 1f).

As can be seen in the UAV images (Fig. 2a), every raft polygon is made of chain-like $P$. yezoensis raft units that are meters apart internally (Fig. 2b). Therefore, the actual fraction of coverage (F) of rafts within every polygon can be expressed as:

$$
\boldsymbol{F}=w /(w+g) * 100 \%
$$

The UAV images collected at multiple sampling points and the statistics of field data indicate that the raft unit is roughly $3 \mathrm{~m}$ wide, and the chain-shaped raft spacing is roughly $9.6 \mathrm{~m}$ (Fig. 2b). This could help to calculate the coverage $\boldsymbol{F}$ of $P$. yezoensis rafts within each polygon, which was about $23.97 \%$. So, the coverage (C) of rafts can be expressed as:

$\boldsymbol{C}=0.24 * \boldsymbol{D}$

The $P$. yezoensis raft area obtained by satellite was substituted into Formula (6), figuring out the area of the actual raft coverage, and finally a drawing was made based on statistics in Arcgis10.1.

\subsection{A calculation model for the initial biomass of the green algae in the radial sand ridge area}

The initial biomass $(\boldsymbol{M})$ of the green algae in the radial sand ridge area equals the product of the raft-attaching green algae coverage and green algae weight per unit, which can be expressed as: 

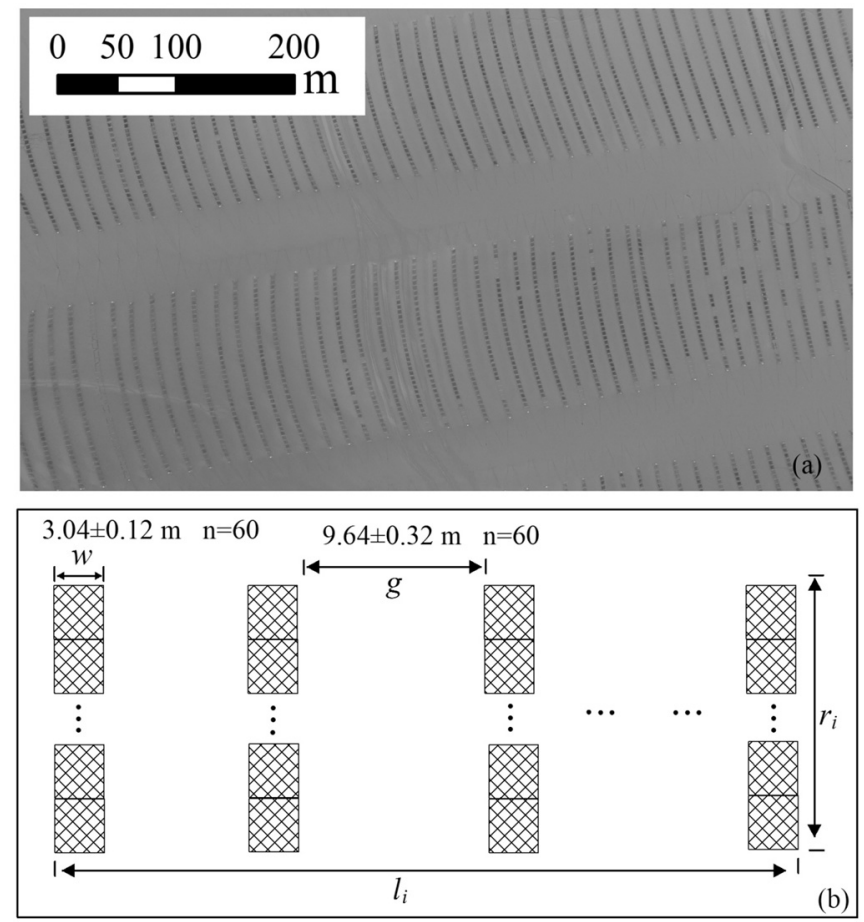

Fig. 2. A model for the $P$. yezoensis rafts in the Radial sand ridge Area: (a) the raft aquaculture pattern photographed by UAV, and the approximately rectangular raft complex were composed of dozens or hundreds of chain-like aquaculture nets; (b) a distribution chart of the aquaculture nets in the raft complex, in which there is even spacing between the aquaculture nets, which are distributed spatially in a regular manner; $\boldsymbol{w}$ represents net width; $\boldsymbol{g}$ represents net spacing.

$\boldsymbol{M}=h * d * \boldsymbol{C}$

where $C$ represents the raft coverage obtained by calculation based on the satellite data; $d$ represents the coverage of the green algae on rafts; $h$ represents the wet weight of green algae per unit.

As shown in Fig. 3, if the green algae on net ropes alone were thrown into the sea, and a $P$. yezoensis polygon was an approximate rectangle (Fig. 2), the length $(\boldsymbol{L})$ of net ropes in all rafts in the radial sand ridge area could be approximately expressed as:

$L=\sum_{i=1}^{N}\left(2 * r_{i} * \frac{l_{i}}{w+g}\right)$

i. e. $L=\frac{2}{w+g} \sum_{i=1}^{\mathrm{N}}\left(r_{i} * l_{i}\right)$

The actual coverage $(C)$ of $P$. yezoensis rafts in the radial sand ridge area could be expressed as:

$\boldsymbol{C}=\sum_{\mathrm{i}=1}^{\mathrm{N}}\left(r_{i} * l_{i}\right)$

The following can be inferred from Formulas (9) and (10):

$\mathbf{L}=\frac{2}{w+g} * \boldsymbol{C}$

According to Formula (11), the length of raft ridge ropes can be directly evaluated based on the raft coverage evaluated according to the satellite data. Hence, the biomass of the green algae on rope of rafts $\left(\boldsymbol{M}_{\text {rope }}\right)$ can be expressed as:

$\boldsymbol{M}_{\text {rope }}=\boldsymbol{L} * S$

where $s$ represents the weight of the green algae on ropes per unit length, which was evaluated based on the survey and sampling.

\section{Results}

\subsection{Identification of raft-attaching green algae based on RGB true-color UAV images}

The statistical results of green tide algae and other ground objects in RGB true-color UAV images are shown in the graph below (Fig. 3c). The graph shows that only green algae's $\mathrm{G}$ (green) band is higher than its $\mathrm{R}$ (red) and $\mathrm{B}$ (blue) bands, while other ground objects' $\mathrm{G}$ band is obviously lower than their $\mathrm{R}$ and $\mathrm{B}$ bands, and green algae show features similar to green vegetation's. This agrees with the result of Cui et al. (2012). Therefore, RGB true-color UAV image-based vegetation indexes can be used to monitor the distribution of green algae on rafts.

Fig. 4 shows the distribution map of four vegetation indexes. A comparison with the raw images suggests that all these four vegetation indexes can well distinguish raft-attaching green algae from others. Fixed thresholding method shows that NGRDI algorithm has the highest accuracy, followed by GLI and NGBDI, with EXG in the last place. It is worth noting that only NGBDI could recognize commonly-used blue nylon ropes on rafts, while the rest ones just classified the ropes as green algae. In addition, all green algae could be identified by NGBDI, but some waters and shadows were mistaken for green algae by NGBDI.

So, we combined NGRDI with NGBDI to identify the green algae on rafts. Firstly, we extracted the green algae by NGBDI and NGRDI respectively. Then the overlap of former results was extracted, and finally the real distribution of raft-attaching green algae was detected.

\subsection{The aquaculture raft area in the radial sand ridge}

The $P$. yezoensis aquaculture raft distribution was extracted in a man-machine interactive mode by ENVI 5.3 as shown in Fig. 1f, a total of 3018 polygons of $P$. yezoensis aquaculture raft were extracted, with a gross area of $229.98 \mathrm{~km}^{2}$. According to Formula (6), we calculated the actual coverage of the $P$. yezoensis aquaculture rafts in the radial sand ridge area, which was $55.08 \mathrm{~km}^{2}$.

The area calculated by us is less than that by Zhang et al. (2014), for the reason that the size of a $P$. yezoensis raft is generally greater than $100 \mathrm{~m}$, whereas a satellite image with a low spatial resolution $(30 \mathrm{~m}$ or lower) often causes an error in raft area evaluation since many mixed pixels. Liu et al. (2010) reported that raft density was 450 per hectare. After a comprehensive satellite-UAV-ground survey, we figured out that the raft density was around 202 per hectare. The density is less than that calculated by Liu as we have considered the error of aquaculture rafts gaps.

\subsection{The initial biomass of the raft-attaching green algae in the radial sand} ridge area

NGRDI was combined with NGBDI to statistically process the UAV images of many raft polygons, the result suggesting that the coverage rate of green algae in the study area was $6.13 \%$. According to the in-situ sampled data of raft-attaching green algae, the wet weight of green algae attaching to raft ropes in the radial sand ridge was $80 \mathrm{~g}$ per meter, and the biomass of pure green algae was $397.14 \mathrm{~g}$ per square meter. Therefore, the biomass of green algae in the radial sand ridge area $(\boldsymbol{M})$ was (according to Formula (7)):

$55.08 \mathrm{~km}^{2} * 6.13 \% * 397.14 \mathrm{~g} / \mathrm{m}^{2} \approx 1340 \mathrm{t}$

The biomass of green algae on raft ropes $\left(\boldsymbol{M}_{\text {rope }}\right)$ in the radial sand ridge area was (Formula (12)):

$2 /(3.04 \mathrm{~m}+9.64 \mathrm{~m}) * 80 \mathrm{~g} / \mathrm{m} * 55.08 \mathrm{~km}^{2} \approx 700 \mathrm{t}$

Huo et al. (2015) argue that there was around 20,000 t of raft-attaching green algae in the radial sand ridge area in 2013, which was higher than our result. One possible cause is that they calculated the biomass of raft-attaching green algae by adopting a relatively higher 


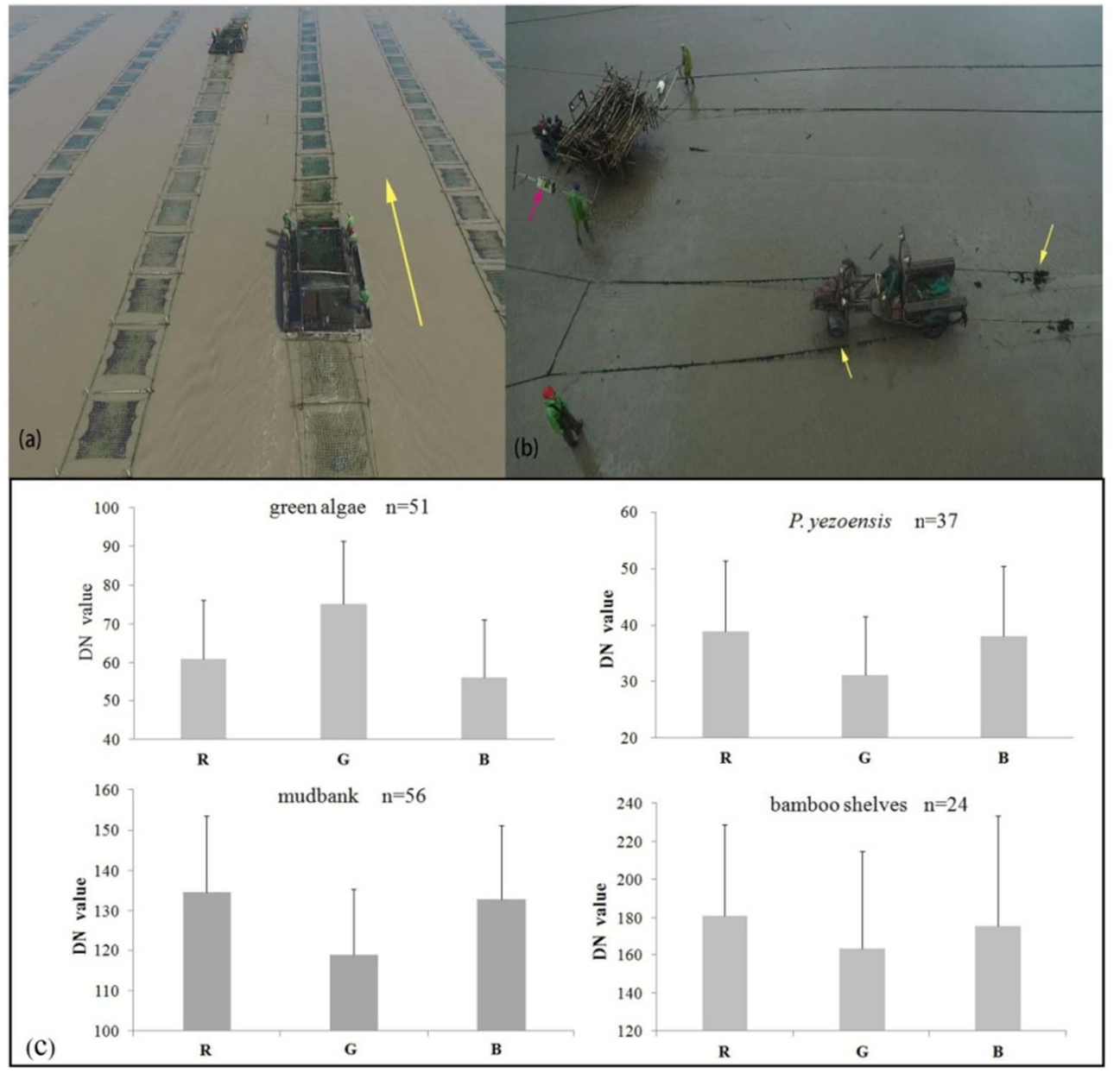

Fig. 3. different processing methods for the green algae on $P$. yezoensis rafts in the radial sand ridge area: (a) all green algae on the nets were harvested and sorted ashore. The yellow array represents the heading direction of the harvesting vessel; (b) the green algae on bamboo shelves at the red arrowhead were brought ashore with the bamboo shelves, and as indicated by the yellow arrow, the green algae on ridge ropes were peeled from the ropes by the tractor; (c) the mean and STD of the three bands of UAV RGB images. raft density (450 per hectare).

\section{Discussions}

\subsection{The application potentiality of $U A V$ in green tide monitoring}

Green tide is nontoxic, but its huge biomass accumulates on the beach on a large scale to destroy the coastal view and cause great losses to the tourism (Wang et al., 2009). Due to its high orbit altitude and wide field of view, satellite remote sensing can scan ground objects on a large scale at a time, so it is often used to monitor green tide on a large scale (Kumar et al., 2015; Xing et al., 2015a, 2015b). But for the regional green tide detection and management, such as coastal landscape, the satellite images cannot meet the temporal and spatial resolution.

UAV technique has emerged as a bridge between ground survey and satellite remote sensing in recent years. Due to its advantages such as flexibility, high spatial resolution, smaller dimensions, and low cost, real-time performance of image transmission and usability in special areas, the UAV could play an important role in eco-environmental monitoring, agricultural production and real-time acquisition of data during natural calamity monitoring. And the UAV has become an important tool in acquiring high-resolution aeronautical data, providing beneficial supplement to ground observation and satellite remote sensing (Wang et al., 2014). Many scholars have monitored red tide by UAV, and obtained satisfactory effect (Shang et al., 2017). Xu et al. (2017) conducted real-time monitoring over the floating green tide for regional green tide monitoring and management by UAV. But there is still little report on how UAV is used for monitoring studies on raftattaching green algae. The results of this study indicate that RGB images captured by UAV can be used to effectively identify the green algae on aquaculture rafts. And the biomass of green algae in the raft zone can be estimated with UAV RGB images and field survey data.

As for the causes of the green tide, scholars generally believe that the green algae attaching to the $P$. yezoensis aquaculture rafts are peeled from rafts and enter the sea and gradually evolve to a green tide disaster (Huo et al., 2015; Liu et al., 2009; Smetacek and Zingone, 2013; Zhang et al., 2014). We also found that lots of green algae on the raft ropes had been thrown into the sea with the aid of the UAV (Fig. 3a and b). To further clarify the mechanism of its occurrence and development, it is necessary to get accurate information of green algae biomass and location. But the complicated environment in the tidal flat area makes it difficult to carry out a scientific survey, and the researchers can only work in a smaller region. However, the UAV, due to its small size and flexibility, provide a better solution for acquisition of such information. Compared with the traditional survey method, comprehensive satelliteUAV-ground survey method has more advantage in green tide monitoring. Satellite image can provide wide field of view of green tide or aquaculture rafts distribution. Moreover, with a few kilometers of the flight radius, UAV can fly to the place where difficult to arrive and provide real-time and high resolution images of the target. It is very useful in the tidal flat survey. This shows that the UAV has a high application value and great potentiality in green tide studies in the future. Thus it is very necessary to continue carrying out monitoring studies on green tide based on satellite-UAV-ground survey method.

\subsection{Pay more attention on monitoring of raft-attaching green algae}

Understanding the initial biomass of green tide can help to reveal recurrence of the green tide in the Yellow Sea over the years. In the present study, an initial biomass estimation model was built for the raft- 

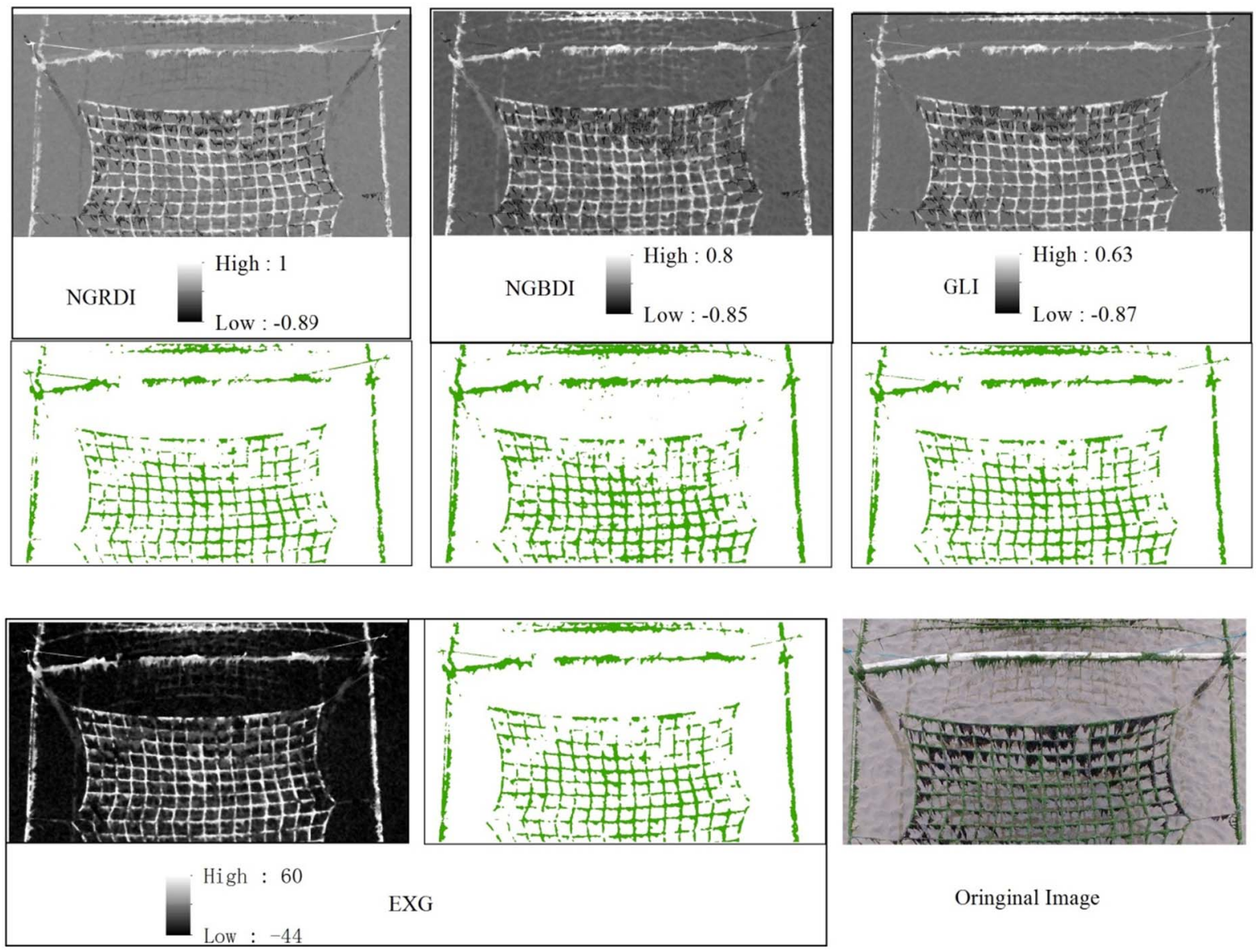

Oringinal Image

Fig. 4. Distribution map of four vegetation indexes and corresponding green algae detected.

attaching green algae in the radial sand ridge area in accordance with high-resolution sentinel images and ground sampling data based on the UAV-based identification of raft-attaching green algae. The results indicated that there were nearly 1000 tons of green algae on rafts in the radial sand ridge area in 2017, 700 tons of which were thrown into the sea after $P$. yezoensis harvest practice. Thrown into the sea, the green algae gathered together and formed stretches of patches in the wind and ocean current, and achieved exponential growth in a suitable nutrient, temperature and illumination condition. The biomass increased by hundreds of times within one month, finally drifting to the coast of the Shandong Peninsula, doing harm to the related coastal zone(Liu et al., 2010).

Researchers have shown that green algae on aquaculture rafts provide initial biomass for the massive propagation of green tide in the South Yellow Sea (Liu et al., 2009, 2010; Keesing et al., 2011). Therefore, accurately monitoring the biomass of raft-attaching green algae can help to forecast the scale of green algae. The latest survey result suggests that green tide propagated on a smaller scale in the Yellow Sea in 2017 than the past, and the biomass decreased by more than half(Zhao, 2017). According to the satellite-UAV-ground estimation model for green algae built in our study, the initial biomass of green algae was less than half of the past years, which had something to do with the change of the $P$. yezoensis aquaculture technology. According to the field survey and monitoring by UAV, due to the increasing level of mechanization, the farmers were more inclined to harvest $P$. yezoensis together with green algae and sort them out ashore this year. As a result, the green algae on rafts were finally discarded ashore instead of thrown to the tide flats directly (Fig. 3a). But for easy formwork removal, the farmers still threw the green algae on raft ropes (Fig. 3b). This may indicates that the blooms scale of green algae can be reduced in the Yellow Sea by improving the $P$. yezoensis aquaculture technology in the radial sand ridge area. However, to further clarify and quantize the relationship between the blooms scale of green tide in the Yellow Sea and the initial biomass of raft-attaching green algae, it is necessary to conduct continuous in-situ field survey in $P$. yezoensis aquaculture zone and pay more attention on raft-attaching green algae.

\section{Conclusions}

Previous studies have indicated that the green tide of the Yellow Sea likely developed from the raft-attaching green algae in the radial sand ridge area. So, it is extremely urgent to evaluate the biomass of raftattaching green algae scientifically and accurately. In this paper, we verified the availability of UAV image-based vegetation index to the identification and monitoring of $P$. yezoensis raft-attaching green algae. An estimation method for the biomass of the raft-attaching green algae based on UAV and S2A images was proposed. The results suggested that: the NGRDI algorithm showed high accuracy in green algae monitoring with UAV images; in 2017, the biomass of the green algae attaching to the $P$. yezoensis aquaculture rafts in the radial sand ridge area was roughly 1340 tons, while that attaching rope was 700 tons, which was lower than previous years. Moreover, the study also demonstrated that our proposed biomass estimation method based on satellite, UAV and field survey could estimate the biomass of raft-attaching green algae with high accuracy. Particularly, the UAV played an important role in green algae discrimination and biomass estimation. Long-term monitoring and field survey on the initial biomass of the raft-attaching green tie algae in the radial sand ridge area will provide theoretical support for revealing the occurrence mechanism of green tide in the Yellow Sea, and may provide a feasible solution for the control and 
early warning of green tide in the Yellow Sea.

\section{Acknowledgements}

We thank Dr. Qingchun Zhang of IOCAS, captain of Lin Wei and other members of the investigative cruises for providing sampling data. This work was supported by Aoshan Science and Technology Innovation Program of Qingdao National Laboratory for Marine Science and Technology (2016ASKJ02), Strategic Priority Research Program of the Chinese Academy of Sciences (XDA11020702), Basic Special Program of Ministry of Science and Technology (2014FY210600).

\section{References}

Blomster, J., Stanhope, M.J., 2002. Novel morphology in Enteromorpha (Ulvophyceae) forming green tides. Am. J. Bot. 89, 1756-1763.

Charlier, R.H., Morand, P., Finkl, C.W., Thys, A., 2015. Green tides on the Brittany coasts. In: Us/eu Baltic International Symposium, pp. 1-13.

Cui, T.-W., Zhang, J., Sun, L.-E., Jia, Y.-J., Zhao, W., Wang, Z.-L., Meng, J.-M., 2012 Satellite monitoring of massive green macroalgae bloom (GMB): imaging ability comparison of multi-source data and drifting velocity estimation. Int. J. Remote Sens. $33,5513-5527$.

Fernández-Manso, A., Fernández-Manso, O., Quintano, C., 2016. SENTINEL-2A red-edge spectral indices suitability for discriminating burn severity. Int. J. Appl. Earth Obs. Geoinf. 50, 170-175.

Hiraoka, M., Ohno, M., Kawaguchi, S., Yoshida, G., 2004. Crossing test among floating Ulva thalli forming 'green tide' in Japan. Hydrobiologia 512, 239-245.

Hu, C., Li, D., Chen, C., Ge, J., Muller-Karger, F.E., Liu, J., Yu, F., He, M.-X., 2010. On the recurrentUlva proliferablooms in the Yellow Sea and East China Sea. J. Geophys. Res. 115.

Hu, L., Hu, C., Ming-Xia, H.E., 2017. Remote estimation of biomass of Ulva prolifera macroalgae in the Yellow Sea. Remote Sens. Environ. 192, 217-227.

Huo, Y., Han, H., Shi, H., Wu, H., Zhang, J., Yu, K., Xu, R., Liu, C., Zhang, Z., Liu, K., He, P., Ding, D., 2015. Changes to the biomass and species composition of Ulva sp. on Porphyra aquaculture rafts, along the coastal radial sandbank of the Southern Yellow Sea. Mar. Pollut. Bull. 93, 210-216.

Jannoura, R., Brinkmann, K., Uteau, D., Bruns, C., Joergensen, R.G., 2015. Monitoring of crop biomass using true colour aerial photographs taken from a remote controlled hexacopter. Biosyst. Eng. 129, 341-351.

Keesing, J.K., Liu, D., Fearns, P., Garcia, R., 2011. Inter- and intra-annual patterns of Ulva prolifera green tides in the Yellow Sea during 2007-2009, their origin and relationship to the expansion of coastal seaweed aquaculture in China. Mar. Pollut. Bull. 62, 1169-1182.

Kumar, L., Sinha, P., Taylor, S., Alqurashi, A.F., Zhou, Y., Kumar, L., Mabee, W., 2015. Review of the use of remote sensing for biomass estimation to support renewable energy generation. J. Appl. Remote. Sens. 9, 205-208.

Lapointe, B.E., Barile, P.J., Littler, M.M., Littler, D.S., 2005. Macroalgal blooms on southeast Florida coral reefs. Harmful Algae 4, 1106-1122.

Lavrova, O.Y., 2016. River plumes investigation using Sentinel-2A MSI and Landsat-8 OLI data. SPIE Remote Sens. 99990G.

Liu, D., Keesing, J.K., Xing, Q., Shi, P., 2009. World's largest macroalgal bloom caused by expansion of seaweed aquaculture in China. Mar. Pollut. Bull. 58, 888-895.

Liu, D., Keesing, J.K., Dong, Z., Zhen, Y., Di, B., Shi, Y., Fearns, P., Shi, P., 2010. Recurrence of the world's largest green-tide in 2009 in Yellow Sea, China: Porphyra yezoensis aquaculture rafts confirmed as nursery for macroalgal blooms. Mar. Pollut. Bull. 60, 1423-1432.

Liu, D., Keesing, J.K., He, P., Wang, Z., Shi, Y., Wang, Y., 2013. The world's largest macroalgal bloom in the Yellow Sea, China: formation and implications. Estuar. Coast. Shelf Sci. 129, 2-10.

Liu, C.C., Xu, R., He, P.M., Zhang, Z.L., Qin, Y.T., Xiang, L.Y., Deng, B.P., Liu, S.H., Ji, X., 2017. Research on the relations between green tide and Porphyra cultivation in the south Yellow Sea. Mar. Sci. 41, 35-43.

Lyons, D.A., Arvanitidis, C., Blight, A.J., Chatzinikolaou, E., Guy-Haim, T., Kotta, J., OravKotta, H., Queirós, A.M., Rilov, G., Somerfield, P.J., 2014. Macroalgal blooms alter community structure and primary productivity in marine ecosystems. Glob. Chang. Biol. 20, 2712-2724.

Nelson, T.A., Nelson, A.V., Tjoelker, M., 2003. Seasonal patterns in ulvoid algal biomass, productivity, and key environmental factors in the Northeast Pacific. Bot. Mar. 46, 263-275.

Qi, L., Hu, C., Xing, Q., Shang, S., 2016. Long-term trend of Ulva prolifera blooms in the western Yellow Sea. Harmful Algae 58, 35-44.

Qiao, F.L., Wang, G.S., Lü, X.G., Dai, D.J., 2011. Drift characteristics of green macroalgae in the Yellow Sea in 2008 and 2010. Chin. Sci. Bull. 56, 2236-2242.

Senthilnath, J., Dokania, A., Kandukuri, M., Ramesh, K.N., Anand, G., Omkar, S.N., 2016. Detection of tomatoes using spectral-spatial methods in remotely sensed RGB images captured by UAV. Biosyst. Eng. 146, 16-32.

Shang, Z.T., 2008. Analysis of the general situations of laver culture in Jiangsu Province and its climatic suitability. J. Anhui Agric. Sci. 36, 5315-5319.

Shang, S., Lee, Z., Lin, G., Hu, C., Shi, L., Zhang, Y., Li, X., Wu, J., Yan, J., 2017. Sensing an intense phytoplankton bloom in the western Taiwan Strait from radiometric measurements on a UAV. Remote Sens. Environ. 198, 85-94.

Smetacek, V., Zingone, A., 2013. Green and golden seaweed tides on the rise. Nature 504, 84-88.

Vega, F.A., Ramírez, F.C., Saiz, M.P., Rosúa, F.O., 2015. Multi-temporal imaging using an unmanned aerial vehicle for monitoring a sunflower crop. Biosyst. Eng. 132, 19-27.

Wang, X.H., Li, L., Bao, X., Zhao, L.D., 2009. Economic cost of an algae bloom cleanup in China's 2008 Olympic sailing venue. EOS Trans. Am. Geophys. Union 90, 238-239.

Wang, C., Yu, R.-C., Zhou, M.-J., 2012. Effects of the decomposing green macroalga Ulva (Enteromorpha) prolifera on the growth of four red-tide species. Harmful Algae 16, 12-19.

Wang, P., Luo, X., Zhou, Z., Zang, Y., Hu, L., 2014. Key technology for remote sensing information acquisitionbased on micro UAV. Trans. Chin. Soc. Agric. Eng. 30, 1-12.

Xing, Q., Hu, C., Tang, D., Tian, L., Tang, S., Wang, X., Lou, M., Gao, X., 2015a. World's largest macroalgal blooms altered phytoplankton biomass in summer in the Yellow Sea: satellite observations. Remote Sens. 7, 12297-12313.

Xing, Q., Tosi, L., Braga, F., Gao, X., Gao, M., 2015b. Interpreting the progressive eutrophication behind the world's largest macroalgal blooms with water quality and ocean color data. Nat. Hazards 78, 7-21.

Xu, Q., Zhang, H., Ju, L., Chen, M., 2014. Interannual variability ofUlva proliferablooms in the Yellow Sea. Int. J. Remote Sens. 35, 4099-4113.

Xu, F., Gao, Z., Shang, W., Jiang, X., Zheng, X., Ning, J., Song, D., 2017. Validation of MODIS-based monitoring for a green tide in the Yellow Sea with the aid of unmanned aerial vehicle. J. Appl. Remote. Sens. 11, 012007.

Zhang, X., Xu, D., Mao, Y., Li, Y., Xue, S., Zou, J., Lian, W., Liang, C., Zhuang, Z., Wang, Q., Ye, N., 2011. Settlement of vegetative fragments ofUlva proliferaconfirmed as an important seed source for succession of a large-scale green tide bloom. Limnol. Oceanogr. 56, 233-242.

Zhang, J., Huo, Y., Wu, H., Yu, K., Kim, J.K., Yarish, C., Qin, Y., Liu, C., Xu, R., He, P., 2014. The origin of the Ulva macroalgal blooms in the Yellow Sea in 2013. Mar. Pollut. Bull. 89, 276-283.

Zhao, B., 2017. http://www.ql1d.com/news/show/id/5379958.html. 